\title{
US healthcare international comparisons: what are we comparing?
}

\section{David W. Jordan*}

School of Business,

Slippery Rock University,

1 Morrow Way, Eisenberg Classroom Building 113,

Slippery Rock, PA 16057, USA

Email: David.Jordan@SRU.edu

*Corresponding author

\section{David Boucher}

Bumrungrad International Hospital,

33 Sukhumvit 3, Wattana,

Bangkok 10110, Thailand

Email: dbouchermph@gmail.com

\begin{abstract}
International comparisons between the US quasi-market and other nations' nationalised healthcare or insurance models have, and continue to generate significant debate. Discussions inevitably cite the World Health Organization's or Commonwealth Fund's work, but what these comparisons actually examine is somewhat unclear when examining the complexity of what is being compared. Often international healthcare comparisons are presented as one based on the quality of healthcare in subject national systems. This paper discusses some of the complexities associated with international comparisons, provides some additional perspectives for metrics often cited in international comparisons, and suggests we may be served better by adjusting the premises of continued discourse in the matter. If the purpose of international comparisons is to evaluate the world laboratory of healthcare policy and processes, which it should, this paper suggests the discussion needs redirected in both focus and content.
\end{abstract}

Keywords: international healthcare comparisons; US healthcare; healthcare model comparisons; quasi-market versus nationalised healthcare insurance or socialised healthcare; single payer versus quasi-market healthcare; international healthcare quality comparisons.

Reference to this paper should be made as follows: Jordan, D.W. and Boucher, D. (2019) 'US healthcare international comparisons: what are we comparing?', Int. J. Healthcare Policy, Vol. 1, No. 1, pp.89-107.

Biographical notes: David W. Jordan's research interests include healthcare benefit design, healthcare management and administrative processes, individual and population health behaviours and factors of healthcare utilisation. $\mathrm{He}$ received his PhD from Virginia Commonwealth University/Medical College of Virginia in Health Services Research - Health Administration, an MBA from the Joseph M. Katz Graduate School of Business University of Pittsburgh, and a Bachelor of Science in Management from the University of Pittsburgh. He was a Regional Vice President and served 22+ years in the insurance and managed care industries prior to joining Slippery Rock University. 
David Boucher is the Chief Business Transformation Officer for Bumrungrad International Hospital, Bangkok, Thailand. He was previously UCI Medical Affiliate's President and COO. Prior to joining UCI Medical, he launched Companion Global Healthcare, an employer-focused medical travel benefits company. He served as CEO at three different facilities with Quorum Health Group and held several executive positions within hospitals. His career began with a Health System Agency in Allentown, Pennsylvania, then worked for BlueCross and BlueShield of South Carolina. David is quoted in over 250 national publications including the NY Times, Washington Post, The Economist, Business Week, Wall Street Journal, Good Housekeeping, The New Yorker, and US News \& World Reports. He has appeared on NBC Nightly News, Fox Business Channel, and presented on disruption innovation at Harvard Business School, Harvard Medical School, Yale University, AARP, and AHIP. He has also lectured at the University of South Carolina School of Public Health.

\section{Introduction}

This paper explores comparisons of US healthcare system quality and associated factors that inform, or fail to inform, such with other developed nations. Comparisons in the literature commonly cited suggest the US healthcare system costs the most and ranks low in quality relative to other developed nations (Davis et al., 2014; Du and Lu, 2016; Squires and Anderson, 2015; World Health Organization, 2000; Claxton et al., 2015). This also suggests the US system represents poor value, as it is a function of quality, outcomes and cost. The USA in this view has become the standard bearer for inefficiency and poor allocation of resources associated with healthcare. The World Health Organization (WHO) ranked the US healthcare system 37th among developed nations in a report cited to this day, the Commonwealth Fund more recently ranked the US healthcare system last of 11 developed nations, and the online executive master of health administration program at George Washington University compared 16 Organization for Economic Co-operation and Development (OECD) nations to identify similar findings (Davis et al., 2014; World Health Organization, 2000; Staff, 2016). These comparisons have become popularised in both media and peer reviewed journal articles (Murray and Frenk, 2010; Munro, 2014; Davis et al., 2014; Du and Lu, 2016).

Although comparisons suggest the US healthcare system compares poorly with other developed nations, a divide persists in societal opinions as to the quality of the US healthcare system. A 2015 Gallup survey finds a large majority of Americans rate their healthcare as excellent or good, $57 \%$ are satisfied with the cost, and $67 \%$ express satisfaction "... with the way the healthcare system is working for them" (Gallup, 2016). Indeed, approximately $73 \%$ of US senior citizens report that they are in good health (Centers for Disease Control and Prevention, 2013). In contrast, 54\% have a "very or somewhat negative" view of the actual US healthcare industry (Gallup, 2016). This negative view also holds true for the Patient Protection and Affordable Care Act (PPACA) with up to $58 \%$ of respondents in favour of repealing the hallmark legislation of the Obama administration (Gallup, 2016). The 2016 presidential election results appear to lend some support for discontent with the PPACA, and efforts continue under the current United States Congress and President Trump's administration to make 
significant changes to the US healthcare system in some incremental form (Kodjak, 2016; Roy, 2016). The key question is why does the US healthcare system fare so poorly in international comparisons, yet public opinion appears generally favourable?

International healthcare system comparisons assess varied attributes of both the systems and their respective populations. Common comparisons heavily weight metrics such as life expectancy, infant mortality, cost and efficiency. These factors are discussed next, followed by additional factors often discussed regarding system quality, however not often discussed relative to the aforementioned international comparisons.

\section{Life expectancy}

Average life expectancy in the world has steadily increased over the past century, including in the US from 49 to 79 years (Arias, 2016). However, it has been argued that much of this is associated with the improvement of sanitation, nutrition and mortality decline from tuberculosis and pneumonia, and not medical intervention (Nbunker, 2001; McKinlay and McKinlay, 1977; McKeown et al., 1976). Only over the past several decades have medical interventions begun to influence average life expectancy (Haughom, 2016).

Increased obesity rates and the prevalence of conditions such as diabetes, heart disease, stroke and cancer have moderated such gains, yet has led to the development of improved interventions to the extent that age adjusted mortality from heart disease has decreased by $56 \%$ since 1960 and by $70 \%$ for stroke since 1950 in the US (Haughom, 2016; Brookings Institute, 2011; Centers for Disease Control and Prevention, 2011; Bradley et al., 2008; Lichtenberg, 2010). Improvements aside, life expectancy is routinely cited as an indicator that the US healthcare system lags behind other developed nations (Davis et al., 2014; World Health Organization, 2000; Roser, 2016; Kaiser Family Foundation, 2015). With an average life expectancy of 79 years of age, the US indeed ranks last of comparable Organization for Economic Co-operation and Development (OECD) countries (Kaiser Family Foundation, 2015). However, life expectancy is dubious at best as a measure of healthcare system quality or effectiveness. Life expectancy is a gross measure that includes many factors well beyond the influence of a nation's healthcare system. Education, ethnicity, behavioural factors, culture, violent crime rates, disease incidence rates and geographic variations contribute significantly to life expectancy (Kaneda and Adams, 2008; Ohsfeldt and Schneider, 2006; OECD, 2015c; Grinshteyn and Hemenway, 2015; Kitawaga and Hauser, 1973; Ferlay et al., 2014; Hogberg, 2006; Baicker et al., 2004). In fact, Americans of Asian descent share similar life expectancy with Japan's average of 83.7 years, which is highest in the world (World Health Organization, 2015). Average Asian American life expectancy is 92.4 in Connecticut, 81.7 in Hawaii and 87.3 overall (Kaiser Family Foundation, 2015; Aid, 2014; OECD, 2015c; Worldlifeexpectancy.com, 2016). One study that controlled for non-health related premature deaths due to accident, crime or injury, finds the adjusted US life expectancy rate was the highest in the world (Ohsfeldt and Schneider, 2006; Manton and Vaupel, 1995). US life expectancy from those who are seventy years and beyond are actually highest among developed OECD nations; such years are those most likely to benefit from medical interventions (Ho and Preston, 2010). This suggests medical intervention in the US may provide greater quality and effect. Life expectancy measures many factors of a nation's health and well-being; however, it serves as a poor 
proxy measure for the quality of the healthcare system (Preston and Ho, 2009; Crimmins, et al., 2011; Manton and Vaupel, 1995).

\section{Infant mortality}

As with life expectancy, infant mortality is often cited as an outcome measure for healthcare system quality ( $\mathrm{Du}$ and Lu, 2016; Davis et al., 2014; World Health Organization, 2000; Staff, 2016; Kaiser Family Foundation, 2015; Ingraham, 2014; Fox, 2015). Infant mortality is a measure that ostensibly captures an outcome after direct access to medical services, which suggests a suitable measure for the quality of care. The US infant mortality rate lags behind other developed nations. The WHO ranks it 41st in OECD nations, The CIA Factbook ranks the US 58th, and the United Nations Population Division ranks it 40th (CIA, 2016; World Health Organization, 2015; Atlas, 2011a; Oestergaard et al., 2011). Infant mortality rates suggest the US healthcare system lags in its level of quality at the point of services rendered in that birth is a point of significant interface with the provision of care in developed nations. This measure however suffers from multiple validity issues. Similar to life expectancy, infant mortality is influenced by ethnicity, geography, income and education (MacDorman et al., 2007; Avasakar, 2012; Goodman et al., 2004; Grady, 2009; Jamison et al., 2004). Variations in infant mortality can differ significantly ranging from 9.6 deaths per 1,000 lives to 4.18 based on geography, and 11.11 to 3.02 based on ethnicity in the US (MacDorman et al., 2007; Centers for Disease Control and Prevention, 2016). Similar variations exist in the UK and Canada as well based on geography (Dorling, 1997).

Infant mortality, as a quality metric, suffers poor or inadequate reporting (Goodman et al., 2004; Woods, 2008). Research finds that three quarters of the world's neonatal deaths are not counted reliably or at all (Lawn et al., 2006; Richardus et al., 1998). However, perinatal mortality rates vary by up to $50 \%$ depending on the definition used to define an infant death (Richardus et al., 1998). Graafmans et al. (2001) finds differences in terminology among developed nations accounts for variations between 14 to $40 \%$ (Graafmans et al., 2001). Infant mortality is 25 times greater for infants under 2,500 grams at birth (Centers for Disease Control and Prevention, 2016). The US counts infant mortality for all births at the point of care including low weight infants and premature births, while countries such as Switzerland deliberately omit low weight infants from mortality statistics (Atlas, 2011a; Zylbersztejn et al., 2017). There is a higher incidence rate of premature births in the USA that significantly increases the risk of death (MacDorman et al., 2007; Wilcox et al., 1995). Birth weight and premature births are associated with ethnicity, particularly for African American teen females, within the highly heterogeneous US population (MacDorman et al., 2007; Centers for Disease Control and Prevention, 2013; O’Neill and O’Neill, 2007; Kleinman and Kessel, 1987; Tuljapurkar and Boe, 1998; MacDorman et al., 2007; Centers for Disease Control and Prevention, 2016). Chen et al. (2016) find that the US actually has a lower prenatal (less than 28 days old) mortality rate than other developed nations when adjusted for birth weight, yet may still lag for post neonatal (28 days to 12 months) mortality rates that they postulate to be associated with socioeconomic disadvantages, which suggests access issues and not quality issues of the care itself (Chen et al., 2016). US population heterogeneity, the reliability of data collection, measurement criteria disparities, the incidence rate for high-risk pregnancies and high risk behavioural factors contrasted 
across nations makes infant mortality a poor measure for healthcare system quality. Furthermore, when adjusted for demographics, measurement disparities and socio-behavioural variables, the US neonatal infant mortality rate is lowest in the world (Chen et al., 2016). However infant mortality is often reported without delineation of such key factors.

\section{Cost and efficiency}

There is very little debate that the US has the highest cost healthcare system in the world. The US healthcare system is the most expensive in the world per capita and percentage of gross domestic product (GDP) (Squires and Anderson, 2015; OECD, 2015b). A 2010 report by the Kaiser Family Foundation indicates a 100\% differential between the lowest cost per capita state and the US cost per capita (Kaiser Family Foundation, 2009).

The question of whether healthcare is a luxury good or a necessity is largely dependent on the level of analysis, if it is examined at the individual risk pool group level versus national system level (Getzen, 2000). Although the level of cost sharing has continued to increase, Americans who are insured at the individual risk pool group level are largely and artificially insulated from the cost of healthcare and enjoy an elasticity of near zero making it a luxury good (Getzen, 2000; Arrow, 2004; Kaiser Family Foundation, 2007; Centers for Medicare and Medicaid Services, 2014). However, at the national level of analysis a nation's healthcare system cost is based on the aggregate spending, in part derived by the supply and wealth of the nation, while considering the percentage of the population who have access to the system (Newhouse, 1977; Getzen, 2000). Getzen (2000) argues that healthcare is both a luxury and a necessity in the US, largely due to the nation's wealth and the willingness to spend at a very high level. Indeed, research suggests a nation's income accounts for $90 \%$ of the variation in healthcare spending among developed nations (Newhouse, 1977). Additionally, a country's level of individual consumption and disposable income are key determinants in national healthcare expenditures (Laakmann, 2017). American households not only spend more on healthcare, however spend more on goods and services overall with greater accumulated wealth than comparative nations (Laakmann, 2017). These characteristics translate to greater healthcare spending, however the OECD Health Purchasing Power Parities (PPP) data suggests such spending is only about $10 \%$ greater than comparative nations when examining the average price of healthcare (Laakmann, 2017).

The US has the largest GDP in the world and the highest level of healthcare supply in terms of technology, specialists, pharmaceuticals, elective surgeries and specialty care along with the most expensive mix of healthcare services including diagnostic screenings and more aggressive end of life forms of care (International Monetary Fund, 2016; Squires and Anderson, 2015; World Health Organization, 2004; Squires, 2012; Fuchs, 2014; Anderson et al., 2003). The US cost of healthcare is also affected by physician pay, which is highest in the world (McAllester, 2012). Higher physician salaries both attract the most qualified and talented, but also drive the cost of care higher. US physicians earn over a third more than Canadian physicians and more than double many others (Laugesen and Glied, 2011; Anderson et al., 2003).

Without question inefficiencies and poor allocation of resources exist in the US healthcare system. However, the willingness or demand, for spending the most on healthcare in the US is not related to poor allocation or inefficiency as much as 
consumers' collective national appetite for what level and types of healthcare is consumed. One factor associated with high cost, or as some may view as inefficient allocation of scarce resources, is the number of orthopaedic procedures that improve functionality and a higher standard of living for many facing non-life-threatening medical conditions. One study examines total knee replacement incidence rates across 31 developed nations for which the US was the highest by a significant margin (De Fatima De Pina et al., 2011). Americans also have a much higher incidence rate of surgical procedures such as costly back surgeries (Cherkin et al., 1994). US healthcare consumers access the healthcare system for procedures covered through government and private insurance that improve their comfort in addition to 'necessary' and lifesaving care. Americans pay more for comfort and convenience (Weeks et al., 2014). Inefficiencies certainly exist; however, they are not unique to the US healthcare system, and in some ways the US performs better (Anderson et al., 2003; Feachem et al., 2002). Countries with lower healthcare spending have largely accomplished this through global budgets and rationing of technology, procedures, specialists and services in general; yet they experience significant inefficiencies in allocation of resources and bureaucracy (Department of Health, 2013; Triggle, 2016; Elliott, 2002; Dobson, 2007; National Health Service, 2012; Deber, 2000; DeCoster et al., 1996; Anderson et al., 2003; Lemieux, 2004; Weeks et al., 2014). Furthermore, the percent of GDP healthcare spending that is government funded is approximately $36 \%$ of US healthcare spending, making the percent of GDP similar to other countries (Centers for Medicare and Medicaid Services, 2014; OECD, 2015b; Lemieux, 2004). This suggests spending over and above this level is driven by consumer demand and the ability to seek such via a quasi-free market. From 2009 to 2013 growth in healthcare per capita spending has remained similar across OECD developed nations, including the US (OECD, 2015b). US consumers actually spent less out-of-pocket than the Swiss, yet spend considerably more than all other nations for private health spending inclusive of insurance premiums, however this metric does not include taxes paid by employees, employers and other specialty taxes that subsidise their systems (OECD, 2007;OECD, 2015b; Squires and Anderson, 2015). One can argue that those costs are quite significant and can influence the alternative use of capital by organisations and individuals. Furthermore, factors associated with US healthcare costs measures are not always represented by other nations. Canada per capita spending does not include capital costs of building and equipment (as in the US); Britain does not include nursing home care costs; costs are hidden such as under-the-table spending in socialised systems to access care more quickly and hidden government administrative or tax revenue collection costs that are included in that recorded by private insurance in the US (Towse and Sussex, 2000; Hensher et al., 1999; Pauly, 1993).

As with life expectancy and infant mortality, demographics and socio-behavioural factors impact healthcare spending. The US has the second highest obesity rate in the world to Mexico, the greatest prevalence of high cost teenage pregnancies, high rates of cigarette smoking, increasing levels of healthcare spending on war veterans, and crime related medical spending in addition to higher rates of R\& D (OECD, 2014; Sedgh et al., 2015; NCVC, 2005; Grinshteyn and Hemenway, 2015; Auerbach et al., 2013; Sotak, 2014). It can be argued that the high prevalence of many conditions and high incidence rates of health risk/high cost associated behaviours in the US are representative of our heterogeneous population and comparatively lower spending on social services. Indeed, the US spends the least percentage of GDP out of eleven nations examined by Bradley 
and Taylor (2013) on social services, and highest on healthcare (Bradley and Taylor, 2013; Squires and Anderson, 2015). The level of a nation's healthcare expenditure does very little to evaluate the quality of the system and more to do with the societal characteristics, consumer demand, wealth, genetic composition and behaviours. In short, the cost of a nation's healthcare is most representative of what the citizens demand and choose to afford as a society, and societal opinion is almost always divided on such key issues.

\section{Measuring quality}

The Institute of Medicine (IOM) defines healthcare quality as the extent health services are provided with improved desired health outcomes for patient populations based on evidence-based knowledge. The IOM also identifies six dimensions or aims: safe, effective, efficient, timely, patient centred and equitable care (Agency for Healthcare Research and Quality, 2017). Of note when discussing national comparisons, four of the six (safe, effective, timely, and patient centred) dimensions receive little analyses, one (efficient) is not frequently discussed from an objective position that includes hidden costs and population characteristics and behaviours, and another (equitable) is highly political and opinion-driven by nature. Varied definitions, processes, reporting infrastructure, and poor quality administrative data challenge international comparisons (Burnett et al., 2013). Of the measures that are available, quality comparisons of healthcare systems internationally may be more objectively assessed via metrics that arguably better represent the six dimensions of quality espoused by the IOM.

\subsection{Safe care}

Iatrogenic care and medical errors are an issue for all countries, however one of the difficulties in assessing safety using such metrics is the failure to report or accurately report either or both. Medical error reporting needs significant improvement yet is relatively robust in the USA compared to other nations, however there are still states that do not require reporting (Schappach, 2014; Unal and Seren, 2016; Howie, 2009). Another metric compared internationally is the incidence rate of Hospital Acquired Infections (HAIs). HAI prevalence is considered to be representative of safe care in high-risk healthcare environments with $20 \%$ of all occurrences considered avoidable (Magill et al., 2014; OECD, 2016). In 2011 one of every 25 US acute care hospital inpatients acquired a HAI, which is lower than all the European Union member states (Magill et al., 2014; OECD, 2016). The European Prevalence of Infection in Intensive Care Study (EPIC) identified a $20.6 \%$ intensive care unit prevalence rate of HAIs (Inweregbu et al., 2005). The US compares favourably with a robust quality-reporting infrastructure in acute care hospitals, even as some nations lack a similar quality management infrastructure and underreport due to lack of associated resources (OECD, 2016; Foley and Burns, 2013; Shaw et al., 2009).

\subsection{Effective care}

Effective care may be viewed from many perspectives, however minimal data is available for international comparisons, and is often in conflict across reporting organisations. 
Outcomes such as breast cancer and prostate cancer post five-year survival rates suggest the US performs well. According to the International Agency for Research on Cancer, affiliated with the WHO, the US ranks ninth both in breast cancer incidence rates (92.9 per 100,000) and five-year post diagnosis survival rates at approximately $63 \%$ versus the top country at of Belgium at $66 \%$ (Soerjomataram et al., 2012). The National Cancer Institute cites breast cancer incidence rates in the US as 125 per 100,000 and post five-year survival rates of $89.7 \%$ (Canadian Institute for Health Information, 2012). The US has the 14th highest incidence rate for prostate cancer with one of the best post fiveyear survival rates of $98.9 \%$ (Soerjomataram et al., 2012).

\subsection{Timely care}

Timely access to healthcare is one of the more distinct contrasts between the US and other nations. Timeliness is also a factor in cost, efficiency and equity because of the method of rationing associated with different healthcare systems. Socialised healthcare systems ration scarce healthcare resources largely by restricting the availability of technology, pharmaceutical products and specialty care through global budgets, whereas the US has historically rationed by cost. The greater availability of technology, specialty care and healthcare infrastructure increases cost. However, that availability includes lower wait times for 'necessary' care, including access to specialists, and elective care such as cataract surgery or hip and knee replacements (Siciliani et al., 2013). Canada, the UK and other socialised healthcare nations historically have long wait times to access diagnostic and specialty care (Canadian Institute for Health Information, 2007; National Health Service, 2016; Shaw et al., 2009; Siciliani et al., 2013; Barua and Ren, 2015; HOPE, 2004). In many cases, wait times extend beyond that which physicians considered clinically reasonable (Barua and Ren, 2015).

\subsection{Patient centred care}

Patient centred care is difficult to measure and compare internationally. The Agency for Healthcare Research and Quality describes it as "(p)roviding care that is respectful of and responsive to individual patient preferences, needs, and values and ensuring that patient values guide all clinical decisions" (Agency for Healthcare Research and Quality, 2017). One study surveyed adults who were sixty-five or older in ten countries and the US (Osborn et al., 2014). Osborn et al. (2014) finds that US respondents were the most likely to have discussed "...health-promoting behaviours with a clinician, to have a chronic care plan tailored to their daily life, and to have engaged in end-of-life care planning" (Osborn et al., 2014). Bekelman et al. (2016) find in a study that examines end-of-life cancer care of seven countries, that the US and Netherlands have the lowest proportion $(22 \%$ and $29.4 \%$ respectively) of persons who die in an acute care facility versus alternative settings and the use of palliative care, respecting patient rights, while also accessing the ICU more commonly in the last 180 days of life (Bekelman et al., 2016). The US also has a robust tort system that likely increases acute care admissions at the end of life associated with physicians' concerns to protect against medical malpractice if they fail to make all medical resources available. This and overuse of diagnostics have led to significant ongoing yet unresolved tort reform debates (Sekhar and Vyas, 2013). 


\subsection{Efficient care}

Lower cost does not equal a more efficient healthcare system. Greater use of advanced technology, cutting edge pharmaceuticals and procedures improve care in the US, however increases cost. In most industries, technology brings efficiencies, however healthcare is one of the few industries that much of new technology increases production costs due to additional specialists, capital investment and additional services rendered (Burns et al., 2011). This too has led to significant debate in the US regarding the cost of technological innovation driven by prohibitive regulatory barriers that drive cost and inhibit disruptive innovation (Graboyes, 2014). Allocation of resources to technologically advanced and cutting-edge care may be a policy debate, however does not equate to inefficiency. Other socialised healthcare systems restrict the use of such advances due to global budget limitations, while they fund such things as spa respites, cooking classes, and ambulance rides to the pharmacy (Department of Health, 2013; Triggle, 2016; Elliott, 2002; Dobson, 2007; National Health Service, 2014; Deber, 2000; DeCoster et al., 1996; Anderson et al., 2003; Lemieux, 2004; Weeks et al., 2014). The focus on primary or preventive care in socialised systems as a more efficient allocation of resources is questionable as only some preventive care is found to be cost effective (Coffield et al., 2001; Cohen et al., 2008; Tengs et al., 1995; Cohen and Neumann, 2009). Other examples of resource allocation, aka 'rationing', in other nations include 'bed-blocking' and the politicisation of resource allocation (Meadowcroft, 2008; Shannon and French, 2005; Maino, 2010; Ross, 2013; Triggle, 2016; Costa et al., 2012). One measure that suggests efficiency in the utilisation of acute care facilities is length of stay (LOS). Shorter LOS represents patient care provided with the least use of costly healthcare resources. LOS in the US is one of the shortest across developed nations at 5.4 days while the OECD average is 8.1 days (OECD, 2015a; American Hospital Association, 2015).

\subsection{Equitable care}

The equitable delivery of medical care is a challenge in most countries on a number of different levels. In the USA, the Joint Commission requires that accredited facilities render care on a single plane without regard or differentiation to the patients' fee-sponsorship. In principle, this suggests that care is rendered in most US hospitals equally regardless of patients' ability to pay. In practice, this is not always the case, especially for elective care. Patients presenting to US hospitals with truly emergent needs are protected via federal statute by the Emergency Medical Treatment and Labor Act (EMTALA) of 1986. As noted previously by the authors, certain types of care (i.e., an outpatient, non-emergent MRI of the knee) are almost considered staples in the US and are readily available in urban and suburban areas within a week or less. Consumers of healthcare in countries that largely rely on public options for medical care (e.g., Canada and Australia) experience wait times in excess of multiple months for this level of non-emergent care (Sicilian et al., 2013). In other countries like Thailand and Costa Rica, this level of care is readily available for local patients with sufficient income to cover the cost, though generally at prices $85 \%$ lower than in the USA. These countries enjoy a much lower regulatory burden and capital structure (Haskins, 2016). 


\subsection{Challenges in comparing quality}

Comparing medical quality amongst providers in the USA is in itself a significant challenge; the effort is even more daunting with international comparisons. In the US, many states require licensed providers, including hospitals, to regularly report certain datasets to assist in documenting credentials, licensing and patient experience information availability. CMS has moved to incorporate patient experiences and value-based metrics in reimbursement levels more vigorously after the Medicare Access and CHIP Reauthorization Act (MACRA) of 2015 (Centers for Medicare and Medicaid Services, 2014). The Commonwealth of Pennsylvania is one such example of timely and thorough reporting (Pennsylvania Department of Health, 2017). A related challenge pertains to both educating and engaging consumers to the level where they actively seek out quality providers through readily accessible channels and to then understand the data they read and act accordingly. US consumers generally place more emphasis in their daily lives on seeking knowledge related to the latest smart phone technology or social media trends, than on identifying a quality healthcare provider as a regular source of care. Although significant challenges of levelling consumers and providers asymmetry of information are very real, it could be argued they are more within the auspices of education, public health, social services and personal responsibility than the actual healthcare delivery system. That said, healthcare experts must continue to focus on new ways to engage and encourage healthcare literacy, to in turn improve consumer adherence to medical recommendations and healthy behaviours.

Other than comparing anecdotal opinions from hospital patient satisfaction surveys (and related posts in social media), comparing specific process and outcome data between hospitals in different countries is nearly impossible with the lack of valid data available that persists today. There are no international data-collecting organisations which share this data with the public. The International Society for Quality in Health Care (ISQuA) accredits the various accrediting bodies such as the Joint Commission International (JCI) and Det Norske Veritas (DNV), but they do not publicly display comparative data. Patient satisfaction stalwart Press-Ganey Associates and outcomes aggregator The Leapfrog Group have little or no international presence. Furthermore, organisations such as the WHO have dubious data, methodology, conclusions and ideological motives to be very informative for an objective analysis (Atlas, 2011b; Whitman, 2008).

Are we really looking at marginalised public health and social services and omnipresent subsidisation of the US social composition and demands for healthcare, the nonmedical factors related to healthcare (Gawande, 2011)? Or does the US healthcare system truly offer inherently low-value healthcare relative to other nations (high cost and inefficient)? The call to acknowledge the imbalance between social services, public health and healthcare delivery is not new, but is too often not central in the debate (Gawande, 2011; Stainton, 2016). Current political debate on US healthcare reform in the US Congress focuses on Medicaid and insurance coverage provisions. The focus on the market distortions caused by payers (government and private insurers) is not new, and is arguably not what measures if the US healthcare system is one of high-quality comparative to other countries; it is one of prioritisation associated with societal demands. The important distinction is between quality provision of care and the access to such care. While it has been demonstrated that the availability, accessibility, and the acceptability of emergent medical care in the USA is, for the large majority of Americans, reasonable, it could be argued that asserting the same for non-emergent, 
elective care would be myopic at best and disingenuous at worst. The confounding factor is another adjective beginning with an ' $a$ ': affordability. Perhaps the largest impediment to satisfying all four of these ideals is to first temper, or 'right-size' the expectation of the American consumer. We actually get what we demand. High cost healthcare in the US has many sources such as lifestyle, a heterogeneous population, the melting pot that makes us so - well - American, regulatory burdens, rights and freedoms that lead to propensities toward costly torts and a greater need of acute care, and non-emergent quality of life care that is at arm's reach within less than a week.

Many would argue that Americans expect the biggest and best of everything, we all want it right now, and when it comes to medical care, none of us want to pay the true price. If we obscure the price through government healthcare and rationing, we may see many individuals benefit, while many others open their eyes to modes of unavoidable (and incontrovertible)rationing that they didn't anticipate. Single payer healthcare in the US would not be 'US healthcare' paid by a single payer, it would be what is available under a single payer system. But the WHO and others continue to frame the US system as 38th in world quality rankings (or something similar) without the honest discussion regarding national and societal priorities, whatever they may be beyond 'healthcare is a right', which itself can be argued vigorously (Williams, 2010). Such comparisons are largely opinion based and biased in their assessment. The most productive analysis and discourse include all legitimate positions of the issues, including the WHO's often cited assessment of equity and justice $A N D$ of quality and value within the context of what is being paid for, demanded and why. They are both valuable and legitimate positions/arguments, but all need to be honestly and accurately presented for what they are with the best evidence available. The generic comparisons/rankings of US healthcare quality have been presented as clearly as mud assuming most will identify with their predetermined passions or needs. We need to debate the different facets of healthcare honestly and transparently to improve the system, including the provision of care, payment, regulation, societal/market demands, social services and public health. Healthcare is not comprised of isolated silos independent of one another. A good start to a healthier debate would include valid and reliable domestic and international constructs and measures for comparison, if we continue to insist on the current us-them analysis.

\section{References}

Agency for Healthcare Research and Quality (2017) The Six Domains of Health Care Quality, U.S. Department of Health \& Human Services [online] http://www.ahrq.gov/professionals/qualitypatient-safety/talkingquality/create/sixdomains.html (accessed May 2017).

Agency for Healthcare Research and Quality (2017) The Six Domains of Health Care Quality, US Department of Health \& Human Services [online] http://www.ahrq.gov/professionals/qualitypatientsafety/talkingquality/create/sixdomains.html (accessed May 2017).

Aid, I. (2014) Do Naturalized Japanese or Foreigners Living in Japan Live as Long as Born-and-Raised in Japan Japanese? [online] http://www.turning-japanese.info/2014/01/ longevity.html (accessed January 2017).

American Hospital Association (2015) TrendWatch Chartbook 2015: Trends Affecting Hospitals and Health Systems [online] http://truecostofhealthcare.org/wp-content/uploads/2018/06/ AHAStatsBook2015.pdf (accessed February 2017).

Anderson, G.F., Reinhardt, U.E., Hussey, P.S. and Petrosyan, V. (2003) 'It's the prices, stupid: why the United States is so different from other countries', HealthAffairs, Vol. 22, No. 3, pp.89-105. 
Arias, E. (2016) Changes in Life Expectancy by Race and Hispanic Origin in the United States, 2013-2014, Centers for Disease Control and Prevention, National Center for Health Statistics.

Arrow, K.J. (2004) 'Uncertainty and the welfare economics of medical care', Bulletin of the World Health Organization, Vol. 82, No. 2, pp.141-149.

Atlas, S. (2011a) 'Infant mortality: a deceptive statistic', National Review [online] https://www.nationalreview.com/2011/09/infant-mortality-deceptive-statistic-scott-w-atlas/ (accessed August 2017).

Atlas, S. (2011b) The Worst Study Ever? Exposing the Scandalous Methods Behind an Extraordinarily Influential, World Heath Report [online] https://www.commentarymagazine. com/articles/the-worst-study-ever/ (accessed August 2017).

Auerbach, D., Weeks, W. and Brantley, I. (2013) Health Care Spending and Efficiency in the U.S. Department of Veterans Affairs, RAND Corporation, Santa Monica, CA.

Avasakar, A. (2012) What are the Factors Affect Infant Mortality Rate? [online] $\mathrm{http}: / / w w w . p r e s e r v e a r t i c l e s . c o m / 2011112918063 /$ what-are-the-factors-affect-infant-mortalityrate.html (accessed 20 November 2016).

Baicker, K., Chandra, A., Skinner, J.S. and Wennberg, J.E. (2004) 'Who you are and where you live: how race and geography affect the treatment of medicare beneficiaries', Health Aff (Millwood), Suppl Variation, Var33-44.

Barua, B. and Ren, F. (2015) Leaving Canada for Medical Care, Fraser Research Bulletin, Fraser Institute [online] https://www.fraserinstitute.org/studies/leaving-canada-for-medical-care-2017 (accessed July 2017).

Bekelman, J.E., Halpern, S.D., Blankart, C.R., Bynum, J.P., Cohen, J., Fowler, R., Kaasa, S., Kweitniewski, L., Melberg, H.O., Onwuteaka-Philispen, B., Oosterveld-Vlug, M., Pring, A., Schreyogg, J.P., Ulrich, C.M., Verne, J., Wunsch, H. and Emanuel, E.J. (2016) ;Comparison of site of death, health care utilization, and hospital expenditures for patients dying with cancer in 7 developed countries', JAMA, Vol. 315, No. 3, pp.272-283.

Bradley, C.J., Yabroff, K.R., Dahman, B., Feuer, E.J., Mariotto, A. and Ml, B. (2008) Productivity Costs of Cancer Mortality in the United States: 2000-2020, National Cancer Institute.

Bradley, E.H. and Taylor, A. (2013) The American Health Care Paradox: Why Spending More Is Getting Us Less, Public Affairs, ISBN 978-61309-209-9 (hbk.: alk. paper); 978-1-61309-2105 (e-book)..

Brookings Institute, B. (2011) 'Deaths from major infectious disease', Health Care, Technology \& Innovation [online] http://www.hamiltonproject.org/charts/deaths_from_major_infectious disease (accessed March 2017).

Burnett, S., Renz, A., Wiig, S., Fernadas, A., Weggelaar, A. M., Calltorp, J., Anderson, J.E., Robert, G., Vincent, C. and Fulop, N. (2013) 'Prospects for comparing european hospitals in terms of quality and safety: lessons from a comparative study in five countries', International Journal for Quality in Health Care, Vol. 25, No. 1, pp.1-7.

Burns, L., Bradley, E. and Weiner, B. (2011) Shortell\& Kaluzny: Healthcare Management: Organization Design and Behavior, 6th ed., Cengage Learning, Clifton Park, NY.

Canadian Institute for Health Information (2007) Wait Times Tables - A Comparison by Province. Analysis in Brief: Taking Health Information Further, Canadian Institute for Health Information [online] https://seer.cancer.gov/statfacts/html/prost.html (accessed February 2017).

Canadian Institute for Health Information (2012) Cancer Stat Facts. Surveillance, Epidemiology, and End Results Program, National Cancer Institute.

Centers for Disease Control and Prevention (2011) National Vital Statistics Reports, Centers for Disease Control and Prevention and National Center for Health Statistics [online] https://www.cdc.gov/nchs/nvss/index.htm (accessed June 2017).

Centers for Disease Control and Prevention (2013) QuickStats. Morbidity and Mortality Weekly Report, Centers for Disease Control and Prevention [online] https://www.cdc.gov/mmwr/ $\mathrm{pdf} / \mathrm{wk} / \mathrm{mm} 6221 . p d f$ (accessed June 2017). 
Centers for Disease Control and Prevention (2016) Infant Health, National Center for Health Statistics: Center for Disease Control and Prevention [online] https://www.cdc.gov/nchs/ fastats/infant-health.htm (accessed June 2017).

Centers for Medicare and Medicaid Services (2014) NHE Fact Sheet, Centers for Medicare and Medicaid Services [online] https://www.cms.gov/research-statistics-data-and-systems/ statistics-trends-and-reports/nationalhealthexpenddata/nhe-fact-sheet.html (accessed November 2016).

Chen, A., Oster, E. and Williams, H. (2016) 'Why is infant mortality higher in the United States than in Europe?', American Economic Journal. Economic Policy, Vol. 8, No. 2, pp.89-124.

Cherkin, D., Deyo, R., Loeser, J., Bush, T. and Waddell, G. (1994) 'An international comparison of back surgery rates', Spine, Vol. 19, No. 11, pp.1201-1206.

CIA (2016) The World Factbook, Central Intelligence Agency [online] https://www.cia.gov/library/ publications/the-world-factbook/rankorder/2091rank.html (accessed November 2016).

Claxton, G., Cox, C., Gonvales, S., Kamal, R. and Levitt, L. (2015) Measuring the Quality of Healthcare in the U.S. [online] http://www.healthsystemtracker.org/insight/measuringthequality-of-healthcare-in-the-u-s/ (accessed August 2016).

Coffield, A.B., Maciosek, M.V., McGinnis, J.M., Harris, J.R., Caldwell, M.B., Teutsch, S.M., Atkins, D., Richland, J.H. and Haddix, A. (2001) 'Priorities among recommended clinical preventive services', American Journal of Preventive Medicine, Vol. 21, No. 1, pp.1-9.

Cohen, J.T. and Neumann, S. (2009) Cost Savings and Cost-Effectiveness of Clinical Preventive Care, The Research Synthesis Project Report No. 18, September 2009, Robert Wood Johnson Foundation, ISSN 2155-3718.

Cohen, J.T., Neumann, P.J. and Weinstein, M.C. (2008) 'Does preventive care save money? health economics and the presidential candidates', New England Journal of Medicine, Vol. 358, No. 7, pp.661-663.

Costa, A.P., Poss, J.W., Peirce, T. and Hirdes, J.P. (2012) 'Acute care inpatients with long-term delayed-discharge: evidence from a Canadian health region', BMC Health Services Research, Vol. 12, p172.

Crimmins, E.M., Preston, C. and Cohen, S.H. (2011) Explaining Divergent Levels of Longevity in High-Income Countries, The National Academic Press, Washington DC.

Davis, K., Stremikis, K., Squires, D. and Schoen, C. (2014) 'MIRROR, MIRROR ON THE WALL: How the Performance of the U.S. Health Care System Compares Internationally, The Commonwealth Fund Website: The Commonwealth Fund [online] https://www.commonwealthfund.org/sites/default/files/documents/__media_files_publication s_fund_report_2014_jun_1755_davis_mirror_mirror_2014.pdf (accessed November 2016).

De Fatima De Pina, M., Ribeirto, A.I. and Santos, C. (2011) 'Epidemiology and variability of orthopaedic procedures worldwide', European Instructional Lectures, Vol. 12, No. 11, pp.9-19, Springer Science \& Business Media.

Deber, R. (2000) Getting What We Pay For: Myths and Realities about Financing Canada's Health Care System. Dialogue on Health Reform: Sustaining Confidence in Canada's Health Care System, National Dialogue on Health Reformed [online] http://www.pnhp.org/docs/ atrevised3.pdf (accessed June 2017).

DeCoster, C., Peterson, S. and Kasian, P. (1996) Alternatives to Acute Care, Manitoba Centre for Health Policy and Evaluation, Manitoba Canada.

Department of Health (2013) Critical Care Bed Capacity and Urgent Operations Cancelled 201213 Data [online] https://www.england.nhs.uk/statistics/statistical-work-areas/critical-carecapacity/critical-care-capacity-data-2012-13/ (accessed November 2017).

Dobson, N.R. (2007) 'Cost effectiveness of heart drugs varies widely, study shows', British Journal of Medicine, Vol. 334, No. 7600, p.922.

Dorling, D. (1997) Death in Britain: How Local Mortalit Rates Have Changed, Joseph Roundtree Foundation [online] http://www.dannydorling.org/wp-content/files/dannydorling_publication id3206.pdf (accessed December 2016). 
Du, L. and Lu, W. (2016) U.S. Health-Care System Ranks as One of the Least-Efficient [online] http://www.bloomberg.com/news/articles/2016-09-29/u-s-health-care-system-ranks-as-one-ofthe-least-efficient (accessed 15 November 2016).

Elliott, V. (2002) 'Bed blockers' farmed out for B\&B recovery', The Times, 9 February.

Feachem, R.G., Seekhri, N.K. and White, K.L. (2002) 'Getting more for their dollar: a comparison of the NHS with California's Kaiser Permanente', British Journal of Medicine, Vol. 324, No. 7330, pp.135-143.

Ferlay, J., Soerjomataram, I., Ervik, M., Dikshit, R., Eser, S., Mathers, C., Rebelo, M., Parkin, D., Forman, D. and Bray, F. (2014) Cancer Incidence and Mortality Worldwide: IARC CancerBase, International Agency for Research on Cancer, Lyon, France.

Foley, M. and Burns, K. (2013) Health Protection Surveillance Centre, Point Prevalence Survey of Hospital Acquired Infections \& Antimicrobial Use in European Acute Care Hospitals: May 2012, Republic of Ireland Critical Care Report, February ed.: HSE - Health Protection Surveylance Centre (HPSC).

Fox, M. (2015) 'U.S. infant mortality rate stays high, report finds', Health News, NBC News.

Fuchs, V.R. (2014) 'Why do other rich nations spend so much less on healthcare?', The Atlantic, 23 July.

Gallup (2016) Gallup Review: Healthcare and the Election [online] https://news.gallup.com/ opinion/polling-matters/196814/gallup-review-healthcare-election.aspx?g source =CATEGORY_HEALTHCARE\&g_medium=topic\&g_campaign=tiles (accessed November 2016).

Gawande, A. (2011) 'The hot spotters: can we lower medical costs by giving the neediest patients better care?', The New Yorker.

Getzen, T. (2000) 'Health care is an individual necessity and a national luxury: applying multilevel decision models to the analysis of health care expenditures', Journal of Health Economics, Vol. 2, No. 19, pp.259-270.

Goodman, J.C., Musgrave, G.L. and Herrick, D.M. (2004) Lives at Risk, Rowman \& Littlefield Publishers Inc, Lanham, Maryland.

Graafmans, W., Richardus, J-H., Macfarlane, A., Rebagliato, M., Blon-Del, B., Verloove-Vanhorick, P.S. and Mackenbach, J. (2001) 'Comparability of published perinatal mortality rates in Western Europe: the quantitative impact of differences in gestational age and birthweight criteria', An International Journal of Obstetrics and Gynaecology, Vol. 108, No. 12, pp.1237-1245.

Graboyes, R. (2014) Fortress and Frontier in American Health Care, Mercatus Center [online] $\mathrm{http}: / /$ mercatus.org/publication/fortress-and-frontier-american-health-care (accessed 12 August 2017).

Grady, S.C. (2009) Geographic analysis of low birthweight and infant mortality in Michigan using automated zoning methodology', International Journal of Health Geographics, Vol. 8, No. 8, pp.1-10.

Grinshteyn, E. and Hemenway, D. (2015) 'Violent death rates: the US compared with other high-income OECD countries, 2010', The American Journal of Medicine, Vol. 129, No. 3, pp.266-73.

Haskins, S. (2016) Why is Healthcare So Much Cheaper Outside the U.S.?, International Living $\mathrm{https}$ ://internationalliving.com/healthcare-much-cheaper-outside-u-s/ (accessed October 2016).

Haughom, J. (2016) What's Good About U.S. Healthcare [online] https://www.healthcatalyst.com/ positive_healthcare_transformation/2016.

Hensher, M., Edwards, N. and Stokes, R. (1999) 'The hospital of the future: international trends in the provision and utilisation of hospital care', British Medical Journal, Vol. 319, No. 7213, p.845.

Ho, J.Y. and Preston, S.H. (2010) 'US mortality in an international context: age variations', Population and Development Review, Vol. 36, No. 4, pp.749-773. 
Hogberg, D. (2006) Don't Fall Prey to Propaganda: Life Expectancy and Infant Mortality are Unreliable Measures for Comparing the U.S. Health Care System to Others [online] http://www.nationalcenter.org/NPA547ComparativeHealth.html (accessed 5 October 2016).

HOPE (2004) Measuring and Comparing - WAITING LISTS - A Study in Four European Countries, Third report of HOPE's Working Party on Management of Waiting Lists. Brussels: Standing Committee of the Hospitals of the European Union.

Howie, W.O. (2009) 'Mandatory reporting of medical errors: crafting policy and integrating it into practice', Journal for Nurse Practitioners, Vol. 5, No. 9, pp.1-7.

Ingraham, C. (2014) 'Our infant mortality rate is a national embarrassment', The Washington Post.

International Monetary Fund (2016) World Economic and Financial Surveys [online] http://www.imf.org/external/pubs/ft/weo/2016/02/weodata/index.aspx (accessed November 2016).

Inweregbu, K., Dave, J. and Pittard, A. (2005) 'Nosocomial infections', Continuing Education in Anaesthesia Critical Care \& Pain, Vol. 5, No. 1, pp.14-17.

Jamison, D., Sandhu, M. and Wang, J. (2004) Why has Infant Mortality Decreased at Such Different Rates in Different Countries?, World Bank, Disease Control Priorities Project, Washington DC.

Kaiser Family Foundation (2007) Insurance Premium Cost-Sharing and Coverage Take-up, KFF [online] http://www.kff.org/insurance/snapshot/chcm020707oth.cfm (accessed August 2008).

Kaiser Family Foundation (2009) Health Care Expenditures per Capita by State of Residence, State Health Facts, Kaiser Family Foundation.

Kaiser Family Foundation (2015) Measuring the Performance of the U.S. Health System, Peterson-Kaiser Health System Tracker. Kaiser Family Foundation.

Kaneda, T. and Adams, D. (2008) Race, Ethnicity, and Where You Live Matters: Recent Findings on Health and Mortality of U.S. Elderly [online] http://www.prb.org/Publications/Articles/ 2008/racialdisparities.aspx (accessed 10 October 2016).

Kitawaga, E.M. and Hauser, P.M. (1973) 'Reviewed work: differential mortality in the United States: a study in socioeconomic epidemiology', American Journal of Sociology, Vol. 80, No. 2, pp.532-534.

Kleinman, J.C. and Kessel, S.S. (1987) 'Racial differences in low birth weight', New England Journal of Medicine, Vol. 317, No. 12, pp.749-753.

Kodjak, A. (2016) 'Trump can kill Obamacare with or without help from congress', Shots Health News from NPR [online] http://www.npr.org/sections/health-shots/2016/11/09/501203831/ trump-can-kill-obamacare-with-or-without-help-from-congress (accessed December 2016).

Laakmann, P. (2017) 'The price is right', National Review, 16 October [online] https://www.nationalreview.com/magazine/2017/10/16/price-right/ (accessed February 2017).

Laugesen, M. and Glied, S.A. (2011) 'Higher fees paid to US physicians drive higher spending for physician services compared to other countries', HealthAffairs, Vol. 30, No. 9, pp.1647-1656.

Lawn, J.E., Wilczynska-Ketende, K. and Cousens, S.N. (2006) 'Estimating the causes of 4 million neonatal deaths in the year 2000', International Journal of Epidemiology, Vol. 35, No. 3, pp.706-718.

Lemieux, P. (2004) 'Canada's 'free' health care has hidden costs', The Wall Street Journal, 23 April [online] https://www.wsj.com/articles/SB108267290367391256 (accessed November 2017).

Lichtenberg, F.R. (2010) Has Medical Innovation Reduced Cancer Mortality, Columbia University and National Bureau of Economic Research.

Macdorman, M., Callaghan, W., Mathews, T., Hoyert, D. and Kochanek, K. (2007) 'Trends in preterm-related infant mortality by race and ethnicity, United States, 1999-2004', International Journal of Health Sciences, Vol. 37, No. 4, pp.635-41. 
Magill, S.S., Edwards , J.R., Bamberg, W., Beldavs, Z.G., Dumyati, G., Kainer, M.A., Lynfield, R., Maloney, M., McAllister-Hollod, L., Nadle, J., Ray, S.M., Thompson, D.L., Wilson, L.E. and Fridkin, S.K. (2014) 'Multistate point-prevalence survey of health care Associated Infections', New England Journal of Medicine, Vol. 370, No. 13, pp.1198-1208.

Maino, F. (2010) 'The Italian health system: cost containment, mismanagement, and politicization', in Baldini, G. and Bull, A. (Eds.): Governing Fear: Italian Politics, Berghahn Books, Oxford.

Manton, K.G. and Vaupel, J.W. (1995) 'Survival after the age of 80 in the United States, Sweden, France, England, and Japan', New England Journal of Medicine, Vol. 333, No. 18, pp.1232-1235.

McAllester, M. (2012) 'America is stealing the world's doctors', The New Your Times Magazine, The New York Times.

McKeown, T., Record, R.G. and Rd, T. (1976) 'An interpretation of the decline of mortality in England and Wales during the twentieth century', Popul. Stud., Vol. 29, No. 3, pp.391-422.

McKinlay, J. and McKinlay, S. (1977) 'The questionable contribution of medical measures to the decline of mortality in the United States in the twentieth century', The Milbank Memorial Fund Quarterly. Health and Society, Vol. 55, No. 5, pp.405-428.

Meadowcroft, J. (2008) ;Patients, politics, and power: government failure and the politicization of U.K. health care', Journal of Medicine and Philosophy, Vol. 33, No. 5, pp.427-444.

Munro, D. (2014) 'U.S. healthcare ranked dead last compared to 10 other countries', Forbes Magazine, 16 June [online] https://www.forbes.com/sites/danmunro/2014/06/16/u-shealthcare-ranked-dead-last-compared-to-10-other-countries/\#533f7794576f (accessed December 2016).

Murray, C.J. and Frenk, J. (2010) 'Ranking 37th - measuring the performance of the US health care system', New England Journal of Medicine, Vol. 362, No. 2, pp.98-99.

National Health Service (2012) Guide to NHS Waiting Times, in (CCGS), N. E. A. C. C. G. (ed.). National Health Service.

National Health Service (2014) Finalised Patient Reported Outcome Measures (PROMs) in England, April 2012 to March 2013, United Kingdom National Health Service [online] http://content.digital.nhs.uk/catalogue/PUB14574 (accessed December 2017).

National Health Service (2016) 'Guide to NHS waiting times', in (CCGS), N.E.A.C.C.G. (Ed.): United Kingdom National Health Service [online] https://www.nhs.uk/usingthe- nhs/nhsservices/hospitals/guide-to-nhs-waiting-times-in-england/ (accessed November 2016).

Nbunker, J.P. (2001) 'The role of medical care in contributing to health improvements within societies', International Journal of Epidemiology, Vol. 30, No. 6, pp.1260-1263.

NCVC (2005) Healthcare Costs of Crime, National Center for Victoms of Crime [online] https:/victimsofcrime.org/docs/Parallel\%20Juctice/PJ-HEALTHCARE\% 20COSTS\%20OF\%20CRIME.pdf?sfvrsn=0 (accessed November 2016).

Newhouse, J.P. (1977) 'Medical-care expenditure: a cross-national survey', The Journal of Human Resources, Vol. 12, No. 1, pp.115-125.

O'Neill, J.E. and O'Neill, D.M. (2007) 'Health status, health care and inequality: Canada vs. the U.S.', NBER program(s): HC HE Forum for Health Economics \& Policy, National Bureau of Economic Research, Berkeley Electronic Press.

OECD (2007) Out-of-Pocket and Private Health Insurance Spending as Share of Total Expenditure on Health, OECD Countries.

OECD (2014) Overweight or Obese Population [online] https://data.oecd.org/healthrisk/ overweight-or-obese-population.htm (accessed November 2016).

OECD (2015a) 'Average length of stay in hospitals', in Health at a Glance 2015: OECD Indicators, in Publishing, O. (Ed.), OECD, Paris.

OECD (2015b) Health Expenditure and Financing, OECD.Stat. [online] https://stats.oecd.org/ Index.aspx?DataSetCode=SHA (accessed November 2016). 
OECD (2015c) Life Expectancy at Birth, OECD Data [online] https://data.oecd.org/healthstat/lifeexpectancy-at-birth.htm (accessed November 2017).

OECD (2016) Healthcare-Associated Infections, Healthcare At A Glance: Europe 2016: State of Health in the EU Cycle, Paris.

Oestergaard, M.Z., Inoue, M., Yoshida, S., Mahanani, W.R., Gore, F.M., Cousens, S., Lawn, J.E. and Mathers, C.D. (2011) 'Neonatal mortality levels for 193 countries in 2009 with trends since 1990: a systematic analysis of progress, projections, and priorities', PLOS Medicine, Vol. 8, No. 8, e1001080 [online] https://doi.org/10.1371/journal.pmed.1001080.

Ohsfeldt, R.L. and Schneider, J.E. (2006) The Business of Health: The Role of Competition, Markets, and Regulation, The AEI Press, Washington, DC.

Osborn, R., Moulds, D., Squires, D., Doty, M.M. and Aderson, C. (2014) 'International survey of older adults finds shortcomings in access, coordination, and patient-centered care', Health Aff., December, Vol. 33, No. 12, pp.2247-2255.

Pauly, M.V. (1993) 'U.S. health care costs: the untold true story', Health Affairs, Vol. 12, No. 3, pp.152-159.

Pennsylvania Department of Health (2017) Pennsylvania Health Statistics [online] https://www.health.pa.gov/topics/HealthStatistics/Pages/health-statistics.aspx (accessed June 2017).

Preston, S.H. and Ho, J.Y. (2009) Low Life Expectancy in the United States: Is the Health Care System at Fault?, PSC Working Paper Series.

Richardus, J., Graafmans, W., Verloove-Vanhorick, S. and Mackenbach, J. (1998) 'The perinatal mortality rate as an indicator of quality of care in international comparisons', Medical Care, Vol. 36, No. 1, pp.54-66.

Roser, M. (2016) Link Between Health Spending and Life Expectancy: US is an Outlier, 3 August, Our World in Data [online] https://ourworldindata.org/the-link-between-life-expectancy-andhealth-spending-us-focus (accessed November 2016).

Ross, T. (2013) 'OECD: bed blocking at highest levels since summer 2010, The Telegraph [online] https://www.telegraph.co.uk/news/health/elder/10131114/OECD-Bed-blocking-at-highestlevels-since-summer-2010.html (accessed November 2013).

Roy, A. (2016) 'Under President Trump, repealing \& replacing Obamacare will be harder than it looks', The Apothecary [online] http://www.forbes.com/sites/theapothecary/2016/11/09/underpresident-trump-repealing-replacing-obamacare-will-be-harder-than-it-looks/-6c48d3747d24 (accessed January 2017).

Schappach, D.L.B. (2014) 'Risk factors for patient-reported medical errors in eleven countries', Health Expect., Vol. 17, No. 3, pp.321-31.

Sedgh, G., Finer, L., Bankole, A., Eilers, M. and Singh, S. (2015) 'Adolescent pregnancy, birth, and abortion rates across countries: levels and recent trends', Journal of Adolescent Health, Vol. 56, No. 2, pp.223-230.

Sekhar, M.S. and Vyas, N. (2013) 'Defensive medicine: a bane to healthcare', Annals of Medical and Health Sciences Research, Vol. 3, No. 2, pp.295-296.

Shannon, V. and French, S. (2005) 'The impact of the re-engineered world of health-care in Canada on nursing and patient outcomes', Nursing Inquiry, Vol. 12, No. 3, pp.231-239.

Shaw, C., Kutryba, B., Crisp, H., Vallejo, P. and Sunol, R. (2009) 'Do European hospitals have quality and safety governance systems and structures in place?', Quality and Safety in Health Care, Vol. 18, No. S1, pp.i51-i56.

Sicilian, L., Moran, V. and Borowitz, M. (2013) Measuring and Comparing Health Care Waiting Times in OECD Countries, OECD Health Working Papers, OECD, Paris.

Soerjomataram, F.J., Ervik, I., Dikshit, R., Eser, R., Mathers, S., Rebelo, C., Parkin, M., Forman, D., Bray, D. and Globocan, F. (2012) Prostate Cancer Statistics, International Agency for Research on Cancer, World Cancer Research Fund International. 
Sotak, J. (2014) 'What's in veterans affairs' \$164 billion budget?', The New York Times, 20 March [online] http://atwar.blogs.nytimes.com/2014/03/20/whats-in-veterans-affairs-164-billionbudget/?_r=2 (accessed 20 November 2016).

Squires, D. (2012) 'Explaining high health care spending in the United States: an international comparison of supply, utilization, prices, and quality', Issues in International Health Policy [online] http://www.commonwealthfund.org/ /media/files/publications/issue-brief/2012/may/ 1595_squires_explaining_high_hlt_care_spending_intl_brief.pdf (accessed November 2016).

Squires, D. and Anderson, C. (2015) U.S. Health Care from a Global Perspective: Spending, Use of Services, Prices, and Health in 13 Countries, Issues in International Health Policy [online] http://www.commonwealthfund.org/ /media/files/publications/issue-brief/2015/oct/ 1819_squires_us_hlt_care_global_perspective_oecd_intl_brief_v3.pdf (accessed 12 November 2016).

Staff, M.G. (2016) U.S. Health Care vs. The World [online] https://mha.gwu.edu/blog/us-healthcare-vs-the-world-2016/. (accessed 11 December 2016).

Stainton, L. (2016) 'Camden coalition's 'hot spotting' approach to healthcare goes national', in NJSPOTLIGHT (Ed.), NJSpotlight [online] http://www.njspotlight.com/stories/16/03/14/ camden-coalition-s-hot-spotting-approach-to-healthcare-goes-national/ (accessed August 2017).

Statistics Canada (2016) Births, Estimates, by Province and Territory, Government of Canada, Statistics Canada.

Tengs, T.O., Adams, M.E., Pliskin, J.S., Safran, D.G., Siegel, J.E., Weinstein, M.C. and Grahm, J.D. (1995) 'Five-hundred life-saving interventions and their cost-effectiveness', Risk Analysis, Vol. 15, No. 3, pp.369-390.

Teutsch, S. (2009) The Synthesis Project, DOI: 10.1056/NEJMp0708558.

Tiggle, N. (2016) 'Hospital bed-blocking 'costs’ NHS England $£ 900 \mathrm{~m}$ a year', BBC, 5 February [online] https://www.bbc.com/news/health-35481849 (accessed November 2016).

Towse, A. and Sussex, J. (2000) 'Getting UK health care expenditure up to the European Union mean' - what does that mean?', BMJ, Vol. 320, No. 7235, pp.640-642.

Triggle, N. (2016) Hospital Bed-Blocking ‘Costs’ NHS England £900m a Year, BBC, 5 February [online] https://www.bbc.com/news/health-35481849 (accessed November 2016).

Tuljapurkar, S. and Boe, C. (1998) 'Mortality change and forecasting: how much and how little do we know?', North American Actuarial Journal, Vol. 2, No. 4, pp.13-47.

Unal, A. and Seren, S. (2016) 'Medical error reporting attitudes of healthcare personnel, barriers and solutions: a literature review', Journal of Nursing \& Care, Vol. 5, p.377, doi:10.4172/2167-1168.1000377.

Weeks, W., Paraponaris, A. and Ventelou, B. (2014) 'Geographic variation in rates of common surgical procedures in France in 2008-2010, and comparison to the US and Britain', Health Policy, Vol. 118, No. 2, pp.215-21.

Whitman, G. (2008) WHO's Fooling Who? The World Health Organization's Problematic Ranking of Health Care Systems, CATO Intstitute, Brief No. 101.

Wilcox, A., Skjaerven, R., Buekens, P. and Kiely, J. (1995) 'Birth weight and perinatal mortality: a comparison of the United States and Norway', JAMA, Vol. 273, No. 9, pp.709-711.

Williams, W.W. (2010) Is Health Care a Right?, Townhall [online] https://townhall.com/columnists/walterewilliams/2010/03/10/is-health-care-a-right-n1181702 (accessed January 2017).

Woods, R. (2008) 'Long-term trends in fetal mortality: implications for developing countries', Bulletin of the World Health Organization, Vol. 86, No. 6, pp.417-496, World Health Organization.

World Health Organization (2000) The World Health Report 2000 - Health Systems: Improving Performance, World Health Report, World Health Organization.

World Health Organization (2004) The World Medicines Situation, World Health Organization [online] http://apps.who.int/medicinedocs/en/d/Js6160e/6.html (accessed November 2016). 
World Health Organization (2015) World Health Statistics 2016 Data Visualizations Dashboard: Newborn and Child Mortality, World Health Organization [online] http://apps.who.int/gho/ data/node.sdg.3-2-viz?lang=en (accessed November 2016).

Worldlifeexpectancy.com (2016) World Health Rankings [online] https://www.worldlifeexpectancy.com/life-expectancy-asia (accessed November 2016).

Zylbersztejn, A., Gilbert, R., Hjern, A. and Hardelid, P. (2017) 'How can we make international comparisons of infant mortality in high income countries based on aggregate data more relevant to policy?', BMC Pregnancy and Childbirth, Vol. 17, p.430 [online] http://doi.org/10.1186/s12884-017-1622-z. 